\title{
Forest biomass estimation using multi-polarization SAR data coupled with optical data
}

\author{
Praveen Kumar* and Akhouri Pramod Krishna \\ Department of Remote Sensing, BIT Mesra, Ranchi 835 215, India
}

This study was carried out to estimate biomass extraction from multi-frequency and multi-polarization of Synthetic Aperture Radar (SAR) data coupled with optical data. Further, the estimated biomass was validated with field-observed data. ALOS-2/PALSAR was utilized for retrieval of forest above-ground biomass (AGB) biophysical parameters. Subsequently, Sentinel-2 optical data and $90 \mathrm{~m}$ TanDEM were used to identify the bare ground area for calculating pseudo height. Ground-truth data were utilized for estimation and validation of the modelled biomass from radar data. In this study, five allometric models were used. Multivariate regression models were trained using backscatter from the same acquisition (date) on 10 randomly selected samples from 21 field plots. The validation was carried out on the remaining 11 field plots. Co-validation method was used to validate these models. Biomass was estimated from radar data using regression models. Since the objective of the study was to present generalized biomass estimation models using backscatter information and AGB, the AGB value range 100-400 tonne/ha was estimated/mapped. Combined backscatter and height inputs were better than backscatter models. In the estimation of AGB, polarimetric information content and backscatter information played a significant role.

Keywords: Allometric model, forest biomass, multifrequency, multi-polarization, optical data.

FOREST is an essential resource of the Earth, catering to the needs of protecting our flora and fauna by regulating their environmental ecosystem. Such ecosystems become an integral part of the socio-economic set-up and have strong bearing on the economy of the society and nation. Fortunately, Jharkhand, India is rich in forest cover having a variety of flora and fauna, and is also known for forest landscapes ${ }^{1}$. Utilization of remote sensing data and techniques for forest biomass estimation is considered significant for a variety of forest tracts. Proper management of forest and its resources has larger implications in carbon sequestration and climate change ${ }^{2}$. There have been significant developments in deriving forest biomass

\footnotetext{
*For correspondence. (e-mail: pkumarbit@gmail.com)
}

and newer innovations in providing more accurate and authentic estimations at various scales, from local to regional to global $^{3-6}$.

In view of climate change, carbon storage assessment is important and forest biomass estimation has a direct link to it. Conventionally, tree height and diameter at breast height $(\mathrm{DBH})$ are used in biomass estimation models $^{7-13}$. Kumar and Krishna ${ }^{14}$ have studied InSAR-based canopy height estimation over hilly forested areas using multitemporal InSAR data pair of Radarsat-1 and Sentinel-1. The ground-measured and interferometric tree heights were compared using three statistical indices with strong correlation of $>80 \%$. In recent years, polarized Synthetic Aperture Radar (SAR) data have been widely used for forest biomass estimation ${ }^{8,15-17}$.

The present study involves developing a better understanding for the estimation of above-ground biomass (AGB) using multi-frequency and multi-polarization ALOS-2/PALSAR data coupled with Sentinel-2 optical data. A biomass estimation model was developed using forest field data of a hilly terrain. SAR is suitable for forest biophysical parameter estimation over natural forests heterogeneous in nature due to its unique penetration potential. Considering a function of polarimetric parameters, nonlinear regression was used to model AGB. The result of regression depicts a significant and strong correlation between polarimetric parameters and referenced $\mathrm{AGB}^{18}$.

Field validation was done considering the topographic elevation variability, different tree heights and $\mathrm{DBH}$. Allometric models were used for validation of AGB derived from SAR data.

The objectives of the present study were to estimate AGB using polarized SAR satellite data for a hilly terrain reserved forest falling within the tropical deciduous broad-leaved forests using regression models and validating with AGB based on field data. AGB was calculated using allometric models and the measured AGB was suitably subjected to regression coefficient estimation. One of the modelling approaches was to retrieve biomass based on a linear function of backscatter in one polarization channel, whereas other allometric models were used with different observables leading to the estimation of pseudo heights and $\mathrm{AGB}^{19-22}$. 

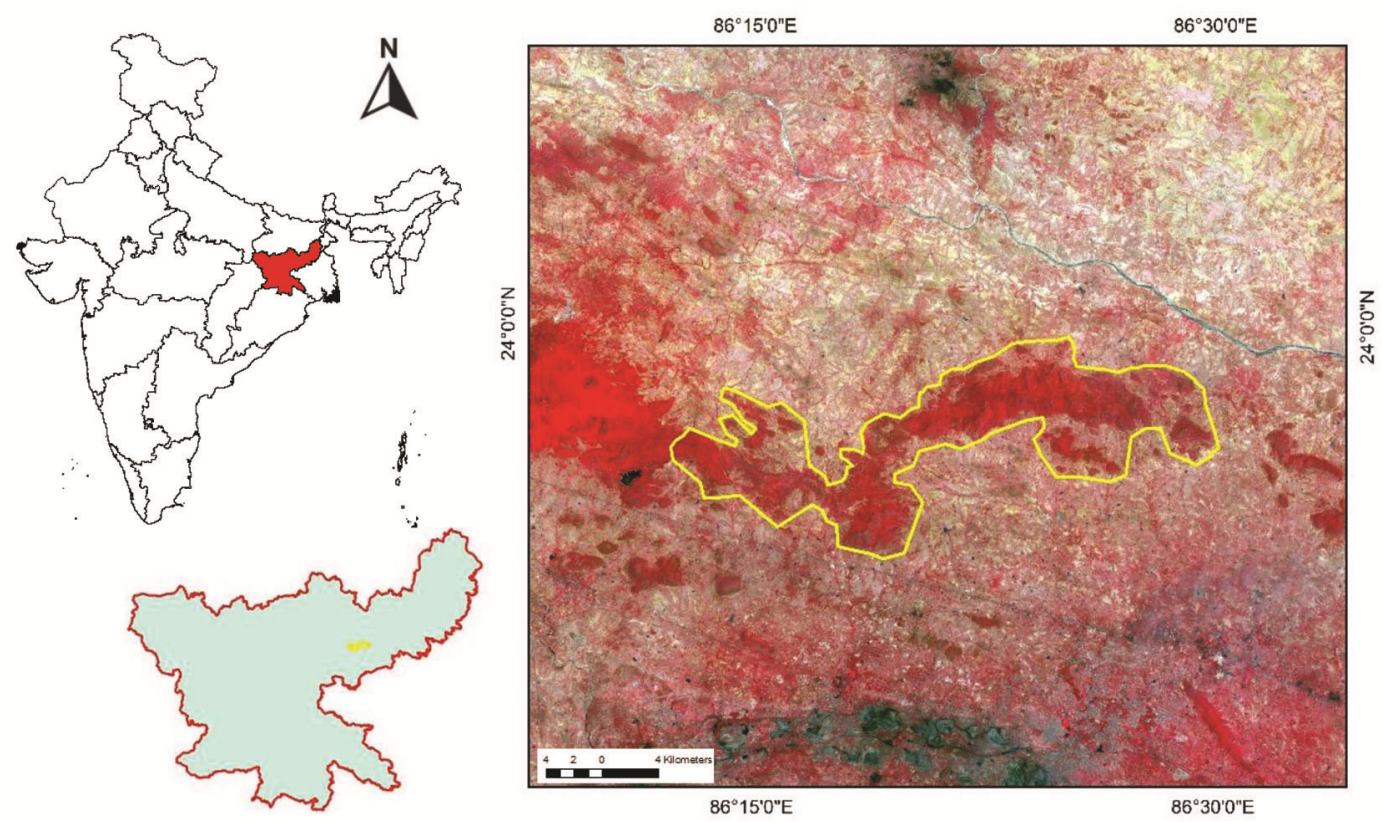

Figure 1. Location map of Tundi Reserved Forest, Jharkhand, India.

\section{Study area}

\section{Test site}

The study area, viz. Tundi Reserved Forest is spread across 144 sq. $\mathrm{km}$ in Dhanbad district, Jharkhand, India. It extends from $23^{\circ} 52^{\prime} 57.37^{\prime \prime}$ to $23^{\circ} 59^{\prime} 44.62^{\prime \prime} \mathrm{N}$ lat. and $86^{\circ} 12^{\prime} 13.49^{\prime \prime}$ to $86^{\circ} 30^{\prime} 58.28^{\prime \prime} \mathrm{E}$ long. It is a typical deciduous forest with total forested area of $23,605 \mathrm{sq} . \mathrm{km}$, constituting about $29.61 \%$ of the total land area of Jharkhand. Out of the total forest land of Jharkhand, $81.28 \%$ is under protected forest and $18.58 \%$ under reserved forest category. The state has two major types of forests, namely tropical zone dry forests and tropical zone wet forests ${ }^{1}$. In the study area, Shorea robusta, commonly known as Sal is dominant and constitutes the top storey of the forest with average height up to $12 \mathrm{~m}$. The test site is dominated by minor hillocks with undulating topography. Figure 1 shows the location map of the study area.

\section{Methodology}

In this study, ALOS-2/PALSAR data acquired on 2 April 2016 over Tundi Reserved Forest were utilized for processing the SAR data to retrieve AGB of the forest. The SAR data were pre-processed before estimating the biomass to correct for errors due to radiometric and geometric distortions, environmental factors and pixel size. The initial step involved radiometric calibration of the data to convert pixel value of the SAR image to backscatter coefficient. The calibrated image was then multilooked to convert the pixels from slant range to ground range by generating $30 \mathrm{~m}$ pixels. This spatial averaging of the range and azimuth resolution cells created an image with reduced speckle noise. Terrain correction was then applied on the multilooked image. Sentinel-2 optical data and DEM generated from $90 \mathrm{~m}$ TanDEM were utilized to identify the ground areas without vegetation for calculating pseudo height at the same locations where field biomass plots were chosen. Biomass was estimated from the polarized radar data $(\mathrm{HH} / \mathrm{HV})$ using regression models. Regression modelling is a statistical approach based on correlating the backscatter measurements at different polarizations with forest biomass. It helps to fit an equation to relate backscatter and AGB. The results obtained from different regression models were compared. The linear regression coefficients were estimated for the models. In this study, five models, viz. M1, M2, M5, M6 and M7 were used.

Models M1 and M2 involve input of either $\mathrm{HH}$ or HV backscatter, or both $\mathrm{HH}$ and $\mathrm{HV}$ backscatter coefficients $^{12,23,24}$.

$$
W_{\mathrm{M} 1}=a_{0}+a_{1}\left[\gamma_{\mathrm{HV}}^{0}\right]
$$

where $a_{0}$ and $a_{1}$ are the model parameters. The next two models add the co-polar channels to obtain a linear regression model, which utilizes the complete polarimetric information ${ }^{24,25}$.

$$
W_{\mathrm{M} 2}=a_{0}+a_{1}\left[\gamma_{\mathrm{HV}}^{0}\right]+a_{2}\left[\gamma_{\mathrm{HH}}^{0}\right]
$$

Models M5-M7 were explored in this study ${ }^{17}$. Model M5, relates forest height to AGB, model M6 relates forest 
height, backscatter and AGB, whereas model M7 relates forest height, both $\mathrm{HH}$ and $\mathrm{HV}$ backscatter, and AGB.

$$
W_{\mathrm{M} 5}=a_{0}+a_{1}\left[H_{X}\right]
$$

where $H_{X}$ is the forest height and $a_{0}$ and $a_{1}$ are the model parameters. Forest height was estimated using DEM derived from $90 \mathrm{~m}$ TanDEM. Models M6 and M7 integrated both backscatter and height to verify for any improvement with the addition of multi-polarimetric information.

$$
\begin{aligned}
& W_{\mathrm{M} 6}=a_{0}+a_{1}\left[H_{X}\right]+a_{2}\left[\gamma_{\mathrm{HV}}^{0}\right], \\
& W_{\mathrm{M} 7}=a_{0}+a_{1}\left[H_{X}\right]+a_{2}\left[\gamma_{\mathrm{HV}}^{0}\right]+a_{3}\left[\gamma_{\mathrm{HH}}^{0}\right] .
\end{aligned}
$$

For measuring AGB of forest in the study area, extensive field survey was carried out. The ground-truth data were utilized for estimation and validation of the modelled biomass from the SAR data. Forest parameters such as $\mathrm{DBH}$, height and biomass plots of 0.1 ha were established during the field inventory for estimation of forest biomass. For each biomass plot, trees with $\mathrm{DBH}$ greater than $15 \mathrm{~cm}$ were considered for measurement. The DBH of a tree is measured at a height of $1.3 \mathrm{~m}$ above the ground (breast level). Allometric equations were used to estimate AGB biomass. The field campaign-estimated forest AGB was accurate, and used for training and validation.

\section{Results and discussion}

Sensitivity of radar backscatter measurements at the Lband to total AGB is discussed here. Multivariate regression models were trained on 10 randomly selected samples from 21 field plots. The validation was carried out on the remaining 11 field plots. Co-validation method was used to validate these models. The models were trained and validated using backscatter from the same acquisition date.

Training and validation plots of AGB values ranged from 100 to $400 \mathrm{mg} / \mathrm{ha}$. To test the model validation two parameters, root mean square error (RMSE) and regression coefficients $\left(R^{2}\right)$ were estimated for each model. The performance of parameters derived from modelling approach was verified using field-measured data. Accuracy of the modelled AGB was estimated using field-measured biomass. RMSE was calculated for the modelled AGB with respect to biomass measured in the field as

$$
\operatorname{RMSE}=\sqrt{\frac{\sum_{i=1}^{N}\left(\mathrm{AGB}_{\text {modelled }(i)}-\mathrm{AGB}_{\text {measured }(i)}{ }^{2}\right)}{N}},
$$

where $N$ is the number of sample plots, $\mathrm{AGB}_{\text {modelled }}$ the modelled $\mathrm{AGB}$ and $\mathrm{AGB}_{\text {measured }}$ is the field-measured biomass. Here the value of $N$ is 21 .
The regression coefficients $\left(R^{2}\right)$ were obtained by fitting a linear regression model line to the backscatter data at each polarization. This represented the saturation of radar signal at higher biomass values. The coefficient of determination was estimated after fitting the goodnessof-fit line for no-intercept models. $R^{2}$ is a measure of how well a linear model fits the data in comparison with a simple average. It is estimated as

$$
\sum R^{2}=1-\frac{\sum\left(\mathrm{AGB}_{\text {measured }}(i)-\mathrm{AGB}_{\text {modelled }}(i)\right)^{2}}{\sum\left(\mathrm{AGB}_{\text {measured }}(i)-\mathrm{AGB}_{\text {mean field-measured }}(i)\right)^{2}},
$$

where $\mathrm{AGB}_{\text {modelled }}$ is the modelled $\mathrm{AGB}$ and $A G B_{\text {measured }}$ is the field-measured biomass.

Subsequently, $R^{2}$ was estimated to evaluate the accuracy of modelled AGB versus estimated AGB for each model.

Figures 2 and 3 show the sensitivity of L-band SAR backscatter to forest biomass. The correlation coefficient for $\mathrm{HH}$ backscatter was 0.51 and that for HV backscatter was 0.50 . The sensitivity of backscatter to biomass was great at lower values of biomass, from about 150 to 250 tonne $\mathrm{ha}^{-1}$. The sensitivity of radar backscatter decreased at high biomass density.

The first approach for a biomass retrieval model was based on a linear function of backscatter in one polarization channel. The values of $R^{2}$ for $\mathrm{HH}$ and $\mathrm{HV}$
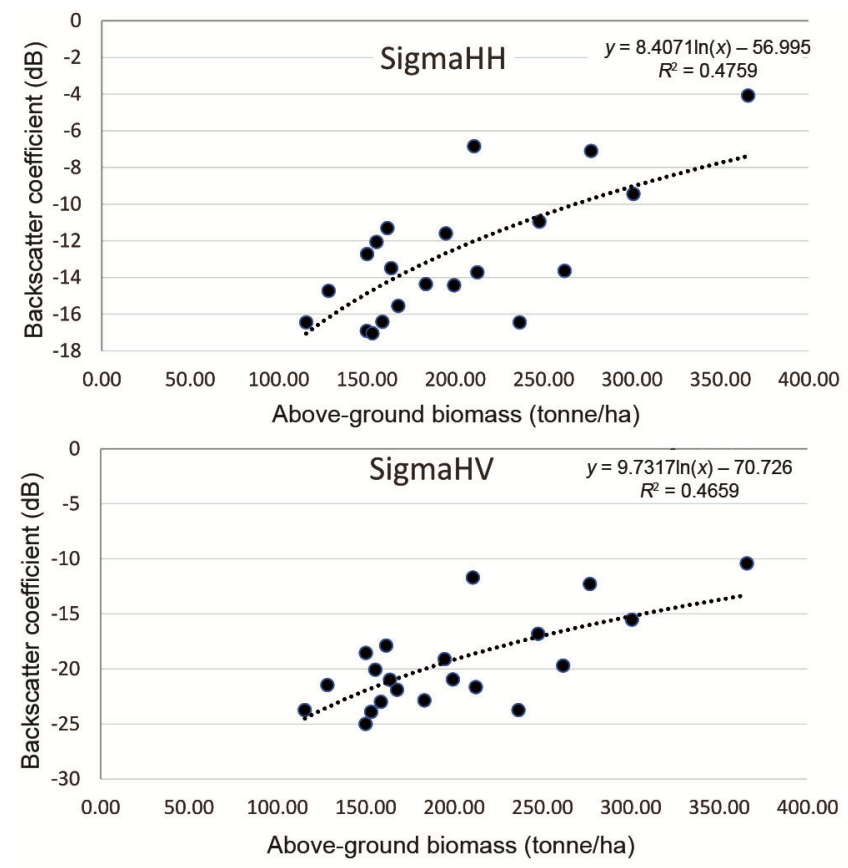

Figure 2. L-band $\mathrm{HH}$ and $\mathrm{HV}$ backscattering coefficients plotted against above-ground biomass (AGB) for fieldwork conducted at Tundi Reserved Forest. Black dots are data points centred on the values of biomass spaced at 50 tonne/ha interval, beginning at zero and running up to 400 tonne/ha. Dotted line is the linear regression trendline. 
were observed to be 0.07 and 0.59 respectively. The RMSE values for $\mathrm{HH}$ and $\mathrm{HV}$ were 56.77 and 53.33 respectively.

Model M2 made use of three observables, and thus four parameters had to be estimated. The addition of another backscatter parameter improved the $R^{2}$ and RMSE values. The $R^{2}$ value thus observed was 0.77 and RMSE was 55.23.

Figures 3 and 4 show the validation performance of the three models, viz. M5-M7 based on RMSE and $R^{2}$ values. For the pseudo heights estimated using TanDEM DEM height difference (Figure 4), the observed differences in the trends for each model is explained below.
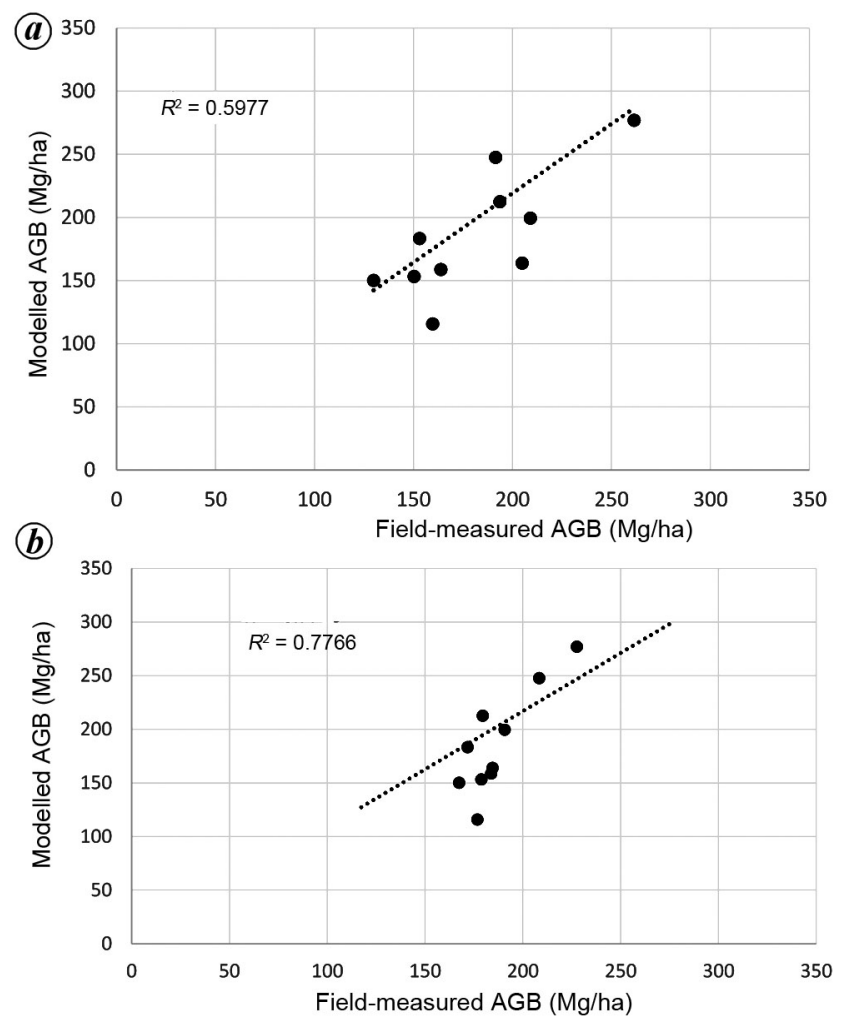

Figure 3. a, L-Band backscatter $\mathrm{HH}$ polarization sensitivity based modelled AGB versus field measured AGB. $\boldsymbol{b}$, L-Band backscatter HV polarization sensitivity based modelled AGB versus field measured AGB.

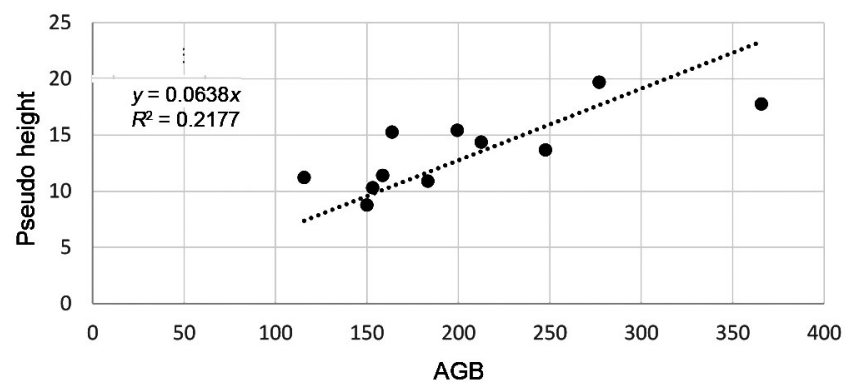

Figure 4. Modelled AGB versus Pseudo height measured.
Model M5 is based only on height. The value of $R^{2}$ is 0.59 and RMSE is 63.18. Hence the model performs poorly for TanDEM height as reflected in AGB modelling.

Figures 5 and 6 show the results of model 6. An increase in $R^{2}$ coefficient is observed. The addition of both $\mathrm{HH}$ and $\mathrm{HV}$ parameters has improved the RMSE compared to the existing models. HV backscatter is strongly related to the AGB and is not much affected by the ground conditions as $\mathrm{HH}$ and $\mathrm{VV}$ polarizations. $R^{2}$ is 0.61 and RMSE is 48.12 for $\mathrm{HH}$ backscatter, while $R^{2}$ 0.618 and $\mathrm{RMSE}=46.15$ for $\mathrm{HV}$ backscatter.

It is interesting to observe the performance of the models with subsequently higher polarimetric information content. From models M1 and M2, the polarimetric information content was found to increase. For models M6 and M7, backscatter and height were given as inputs. With the addition of polarimetric information in M6 and M7, there was an improvement in model performance. The improvement with addition of cross-pol backscatter

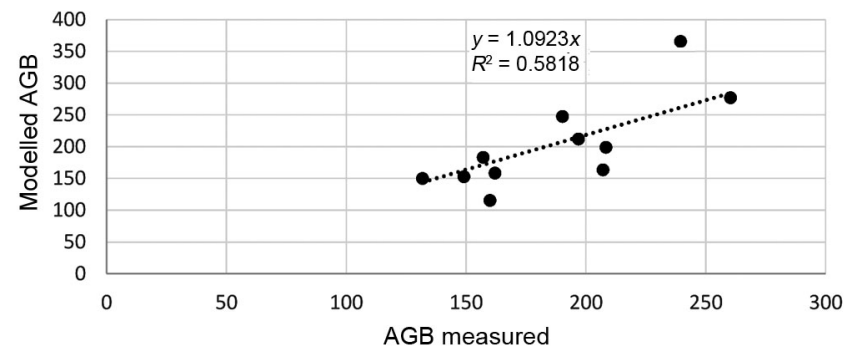

Figure 5. Modelled AGB versus AGB measured for $\mathrm{HH}$ backscatter with 10 training samples.

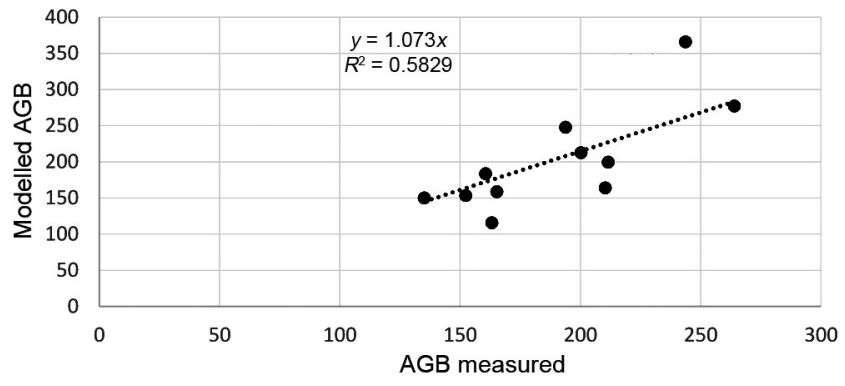

Figure 6. Modelled AGB versus field measured AGB for HV backscatter for 10 training samples.

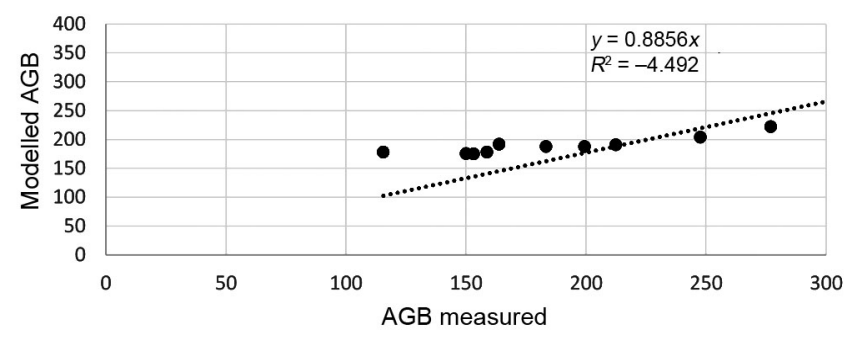

Figure 7. Modelled AGB versus field-measured AGB for 10 training samples. 


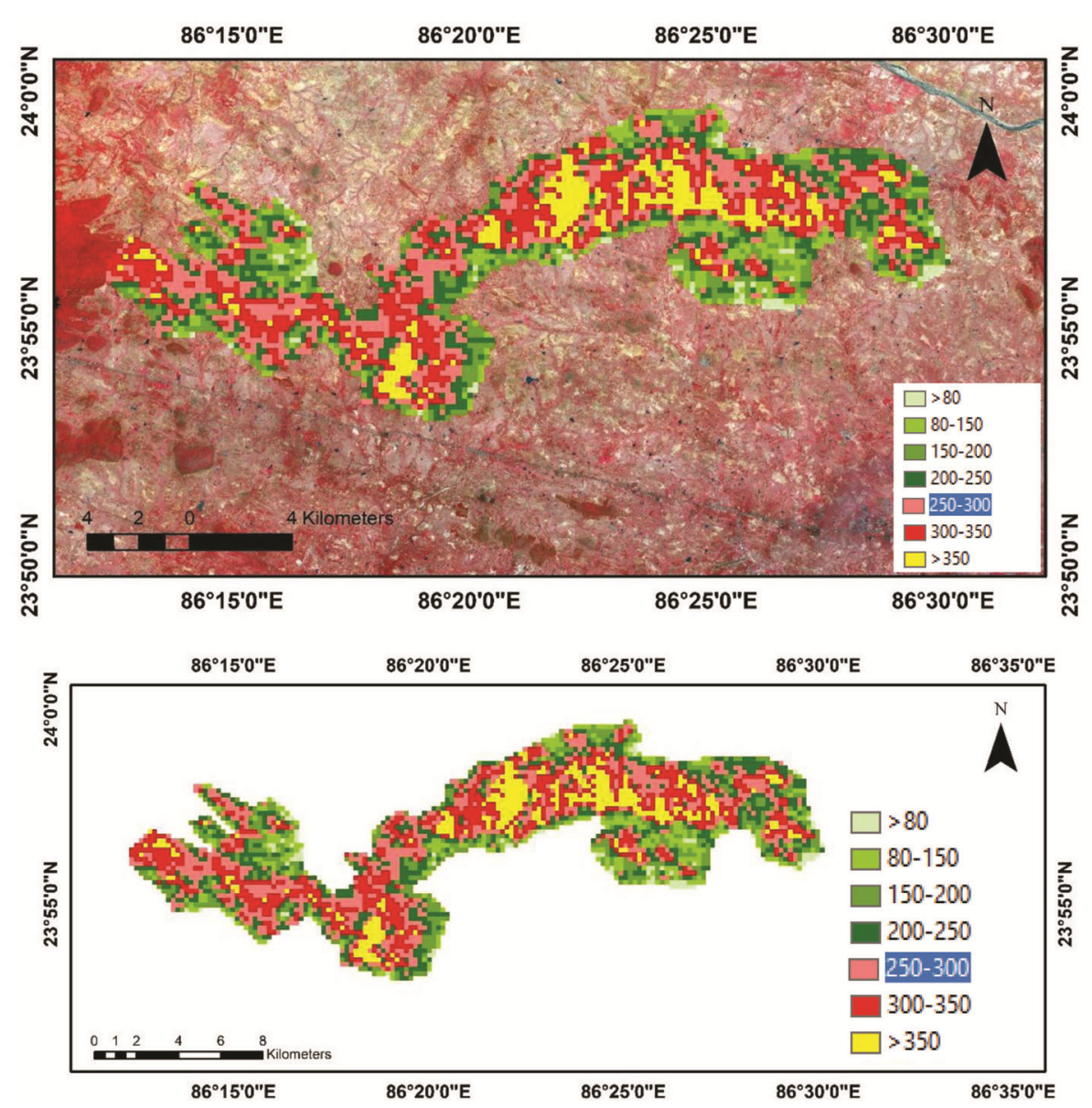

Figure 8. AGB map of Tundi Reserved Forest.

in model M6 was significant. With the addition of height, the models with combined backscatter and height input performed significantly better than the backscatter-only models. The model inversion improved with reducing RMSE for model M6. This model had input of only the cross-pol backscatter. Model M7 had additional HH-pol backscatter information. Among the five models chosen, M7 had the highest accuracy (Figure 7; RMSE = 44.20).

An AGB map was prepared using backscatter information presenting generalized biomass estimation models (Figure 8).

\section{Conclusion}

In this study we have estimated AGB using multi-frequency and multi-polarization SAR data (ALOS-2/PALSAR) coupled with optical data (Sentinel-2). This allowed inferences on backscatter and concurrent $\mathrm{AGB}$ values using optimal number of sample plots and a contiguous range of derived AGB values. Field sample plots served as training and validation plots within the AGB value range 100-400 tonne/ha. The model validations showed acceptable ranges of RMSE and $R^{2}$ values. One of the approaches in this study was a biomass retrieval model based on linear function of backscatter in one polarization channel. $R^{2}$ and RMSE values for $\mathrm{HH}$ and HV were useful in establishing modelled AGB model versus groundmeasured AGB values.

It was further observed that the models should have higher polarimetric content, when comparing M2 and M1. Similarly, M6 and M7 showed that with the addition of polarimetric information, the model performance improved. Combined backscatter and height inputs were noted to be better than backscatter models. Ultimately depending on the performance of these models in the estimation of $\mathrm{AGB}$, it was found that the polarimetric information content and backscatter information proved vital and significant. This study has thus brought out the efficacy of SAR data for biomass estimation exhibiting better potential for AGB mapping.

1. India State of Forest Report 2019, Forest Survey of India, Ministry of Environment, Forest and Climate Change, Government of India, 2019, vol. II, pp. 112-120.

2. Ann, B., Why biomass is important - the role of the USDA Forest Service in managing and using biomass for energy and other uses. USDA's Research, Education, and Economics (REE) mission area, 2012; https://www.researchgate.net/publication/237397345. 
RESEARCH ARTICLES

3. Galileo SAR Service Definition Document - European GNSS, SAR/Galileo Service Centre (SGSC), Toulouse (France), 2.0, 2020, pp. 7-64.

4. Zebker, H. A. and van Zyl, J. J., Imaging Radar Polarimetry: a review. Proc. IEEE, 1991, 79(11), 1583-1606.

5. Hajnsek, I., Scheiber, R., Keller, M., Horn, R. and Lee, S., Technical Assistance for the Development of Airborne SAR and Geophysical Measurements during the BioSAR 2008 Experiment, Earth Observation Programme, Microwaves and Radar Institute (DLR-HR), German Aerospace Center (DLR), European Space Agency (ESA), Wessling, Germany, Final report, 2009, 1-1, pp. 9-285.

6. Rauste, Y. T., Häme, J. P., Heiska, K. and Hallikainen, M., Radarbased forest biomass estimation. Int. J. Remote Sensing, 1994, 15(14), 2797-2808.

7. Hurtado, D. M., Interferometric Processing of TanDEM-X Images for Forest Height Estimation, Final Report, Department of Radio Science and Engineering, School of Electrical Engineering, Aalto University, 2012, pp. 16-98.

8. Neumann, M., Famil-Ferro, L. and Reigber, A., Estimation of forest structure, ground, and canopy layer characteristics from multibaseline polarimetric interferometric SAR data. IEEE Trans. Geosci. Remote Sensing, 2010, 48(3), 1086-1104; doi:10.1109/ TGRS.2009.2031101.

9. Zaki, N. A., Mohd, Latif, Z., Abd, Suratman, M. N. and Zainal, M. Z., Aboveground biomass and carbon stocks modelling using nonlinear regression model. IOP Conf. Ser. Earth Environ. Sci., 2016, 37(1), 2-10; doi:10.1088/1755-1315/37/1/012030.

10. Ghulam, A., Porton, I. and Freeman, K., Detecting subcanopy invasive plant species in tropical rainforest by integrating optical and microwave (InSAR/PolInSAR) remote sensing data, and a decision tree algorithm. ISPRS J. Photogramm. Remote Sensing, 2014, 88, 174-192.

11. Rignot, E., Zimmermann, J. R. and van Zyl, J. J., Spaceborne applications of $\mathrm{P}$ band imaging radars for measuring forest biomass. IEEE Trans. Geosci. Remote Sensing, 1995, 33(5), 1162 1169 .

12. Askne, J. I. H., Fransson, J. E. S., Santoro, M., Soja, M. J. and Ulander, L. M. H., Model-based biomass estimation of a hemiboreal forest from multitemporal TanDEM-X acquisitions. Remote Sensing, 2013, 5(11), 5574-5597.

13. Nguyen, T. N., Estimation and mapping of above ground biomass for the assessment and mapping of carbon stocks in tropical forest using SAR data: a case study in Afram headwaters forest, Ghana, Thesis, International Institute for Geoinformation Science and Earth Observation, University of Twente, ITC, the Netherlands, 2010, p. 79

14. Kumar, P. and Krishna, A. P., InSAR-based tree height estimation of hilly forest using multitemporal radarsat-1 and sentinel-1 SAR data. IEEE J. Sel. Top. Appl. Earth Obs. Remote Sensing, 2019, 12(12), 5147-5152.

15. Khati, U. and Singh, G., Temporal analysis of polinsar based forest height inversion for tectona grandis and eucalyptus plantations. In International Geoscience and Remote Sensing Symposium
(IGARSS) 2016, Beijing, China, 2016, pp. 4702-4705; doi:10.1109/IGARSS.2016.7730227.

16. Kugler, F., Schulze, D., Hajnsek, I., Pretzsch, H. and Papathanassiou, K. P., TanDEM-X Pol-InSAR performance for forest height estimation. IEEE Trans. Geosci. Remote Sensing, 2014, 52(10), 1 19; doi:10.1109/TGRS.2013.2296533.

17. Khati, U., Singh, G. and Mohanty, S., Forest biophysical parameter estimation using space-borne bistatic PolIn SAR measurements, SPIE 9877, land surface and cryosphere remote sensing III. Proc. SPIE, 2016, 9877, 7; doi:10.1117/12.2222741.

18. Waqar, M. M., Sukmawati, R. J., Yaqi, S. S. and Josaphat, T., Tropical peat land forest biomass estimation using polarimetric parameters extracted from Radar SAT-2 images, MDPI journals, Special Issue Multiscale Geospatial Approaches for Landscape Ecology. Land, 2020, 9(6), 193; doi:10.3390/land9060193,2020,1-20.

19. Zhang, F., Xu, M., Xia, Z., Wan, Z., Li, K. and Li, X., Forest mapping using bi-aspect polarimetric SAR data in southwest China, MIPPR 2009: Multispectral Image Acquisition and Processing. Proc. SPIE-Int. Soc. Optical Eng., 2009, 7494, 74940W1-8; doi:10.1117/12.833185.

20. Schuler, D. L., Lee, J. S. and Grandi, G. De, Measurement of topographic surface slopes using polarimetric SAR images. In International Geoscience and Remote Sensing Symposium (IGARSS'94): Surface and Atmospheric Remote Sensing: Technologies, Data Analysis, and Interpretation, California Institute of Technology, Pasadena, California, USA, 8-12 August 1994, vol. 3, pp. 1467-1469.

21. Lee, J. S., Grunes, M. R., Ainsworth, T., Hajnsek, I., Mette, T. and Papathanassiou, K. P., Forest classification based on L-band polarimetric and interferometric SAR data. In European Space Agency (Special Publication), 2005, no. 586, 31-37.

22. Hagberg, J. O., Ulander, L. M. H. and Askne, J., Repeat-pass SAR Interferometry over Forested Terrain. IEEE Trans. Geosci. Remote Sensing, 1995, 33(2), 331-340; doi:10.1109/36.377933.

23. Le Toan, T. et al., The BIOMASS mission: mapping global forest biomass to better understand the terrestrial carbon cycle. Remote Sensing Environ., 2011, 115(11), 2850-2860.

24. Soja, M. J., Sandberg, G. and Ulander, L. M. H., Regression-based retrieval of boreal forest biomass in sloping terrain using P-band SAR backscatter intensity data. IEEE Trans. Geosci. Remote Sensing, 2013, 51(5), 2646-2665.

25. Saatchi, S., Halligan, K., Despain, D. G. and Crabtree, R. L., Estimation of forest fuel load from radar remote sensing. IEEE Trans. Geosci. Remote Sensing, 2007, 45(6), 1726-1740.

ACKNOWLEDGEMENTS. We thank the scientists at IIT-Bombay, and SAC, ISRO, Ahmedabad for their help at various stages of this study. We also thank BIT Mesra, Ranchi for support, and the anonymous reviewers for constructive comments that helped improve the manuscript.

Received 27 June 2020; revised accepted 7 August 2020

doi: $10.18520 / \mathrm{cs} / \mathrm{v} 119 / \mathrm{i} / 1316-1321$ 